\title{
Blood parameters of young calves at abattoirs are related to distance transported and farm of origin
}

\author{
Natalie Roadknight, ${ }^{1,2 *}$ ๑ Peter Mansell, ${ }^{2} \odot$ Ellen Jongman, ${ }^{1,2} \odot$ Natalie Courtman, ${ }^{2} \odot$ David McGill, ${ }^{2}$ \\ Graham Hepworth, ${ }^{3}$ (1) and Andrew Fisher ${ }^{1,2}$ (1) \\ ${ }^{1}$ Animal Welfare Science Centre, The University of Melbourne, Parkville, Victoria 3052, Australia \\ ${ }^{2}$ Faculty of Veterinary and Agricultural Sciences, The University of Melbourne, Werribee, Victoria 3030, Australia \\ ${ }^{3}$ Statistical Consulting Centre, The University of Melbourne, Carlton, Victoria 3053, Australia
}

\begin{abstract}
Nonreplacement dairy calves, or bobby calves, are fasted and transported to abattoirs from as young as 5 $\mathrm{d}$ of age in Australia. The aims of this cross-sectional observational study were (1) to assess the welfare status, as measured by blood parameters, of bobby calves in the commercial supply chain after transport and lairage, and (2) to assess whether distance and duration of transport are risk factors for poor bobby calf welfare, as measured by blood parameters. We hypothesized that bobby calves transported greater distances would be more likely to show evidence of compromised welfare, as measured by blood indicators of hydration, energy status, and muscle fatigue or damage. We also hypothesized that there would be a large amount of variability in indicators of energy status between calves from different farms. We analyzed blood samples collected at slaughter over a spring and an autumn calving period from 4,484 Australian bobby calves aged approximately 5 to $14 \mathrm{~d}$ old from 3 different states, after transport, fasting, and lairage. Packed cell volume (PCV), plasma glucose, and serum urea, total protein, $\beta$-hydroxybutyrate (BHB), and creatine kinase $(\mathrm{CK})$ were measured. Radio frequency identification ear tag data were used to estimate the distance that the calves were transported and to identify the farm of origin. Data were analyzed using linear mixed models, except for BHB, which was analyzed using a Goodman-Kruskal gamma test due to left censoring of the data. Twelve percent of calves showed evidence of anemia (PCV less than $0.23 \mathrm{~L} / \mathrm{L}$ ), and $11 \%$ had urea concentrations consistent with dehydration (urea more than $7.7 \mathrm{mmol} / \mathrm{L}$ ). Thirty-six percent of calves had CK activity above normal resting values, and $1 \%$ of calves had CK $>2,000 \mathrm{U} / \mathrm{L}$, indicating muscle fatigue or damage. Distance transported had significant effects on all
\end{abstract}

Received October 2, 2020.

Accepted March 30, 2021

*Corresponding author: nroadknight@gmail.com blood variables except urea and BHB. With increasing distance transported, calves were more likely to show evidence of a negative energy balance (low plasma glucose) or dehydration (high PCV or total protein). The estimated effect of distance overall was small, but for calves transported more than $500 \mathrm{~km}$, plasma glucose concentration declined more per kilometer. The calves' farm of origin accounted for a reasonable amount of the random variation between calves for plasma glucose $(20 \%)$. Our results suggest that longer transport distances may increase the risk of poor calf welfare (dehydration, negative energy balance) after transport, and on-farm calf management (e.g., nutrition, timing of feeding before transport) may affect transported calves' energy status; improving this area could result in better energy availability during fasting.

Key words: nonreplacement, blood, serum, dairy, dairy-veal

\section{INTRODUCTION}

Nonreplacement dairy calves, also known as bobby calves, are calves that are born on dairy farms to facilitate milk production in their dam, but which are either male or surplus to replacement heifer requirements for the farm. In New Zealand and Australia, bobby calves can legally be transported from farms to abattoirs for slaughter when they are $4 \mathrm{~d}$ (New Zealand) or $5 \mathrm{~d}$ old (Australia), or older (Animal Health Australia, 2012; New Zealand Government, 2018). Bobby calves may be transported to a saleyard and then on to an abattoir, or directly to an abattoir. In Australia, slaughter often occurs on the morning following arrival, so an overnight period of lairage, without food, can occur. The transport and lairage process involves several risks to the welfare of calves, including fasting, transport stress, handling, social stress, injury, and disease.

Although transport combined with fasting is recognized as a stressful experience for cattle of any age (Warriss et al., 1995; Grandin, 1997; Knowles, 1999), neonatal calves may be at an especially high risk of 
welfare compromise during transport and fasting. This is due to several reasons. First, young calves have low body fat reserves (Bell, 1979), which puts them at a higher risk of energy depletion during the fasting that accompanies transport and lairage. Second, young calves have a relatively high risk of morbidity and mortality, and this risk is increased with failure of passive transfer, which occurs in an estimated 33 to $42 \%$ of Australian dairy calves (Vogels et al., 2013; Abuelo et al., 2019). Calf morbidity and mortality risks could also be further increased when combined with the stresses associated with transport, such as handling, novelty, reduced opportunities to rest, and fasting (Trunkfield and Broom, 1990; Hulbert and Moisá, 2016). Third, young calves may be unsteady on their feet; calves have been reported to have a higher incidence of falls during transport, compared with adult cattle (Cockram and Spence, 2012). Finally, young calves have not yet learned herding and following behavior, and this can make them more difficult to handle (Jongman and Butler, 2013), particularly at loading and unloading. This difficulty may increase calves' risk of poor handling in relation to transport.

Several studies have assessed the effects of transport and fasting on young calf welfare in an experimental setting. Most of these studies used selected serum biochemistry and hematology values as part of the welfare assessment (e.g., Knowles et al., 1997; Todd et al., 2000; Fisher et al., 2014). For example, packed cell volume (PCV), urea, and total protein have all been used to assess hydration status in young transported calves (Knowles et al., 1997; Todd et al., 2000; Fisher et al., 2014), and glucose and BHB have been used as indicators of energy balance (Knowles et al., 1997; Todd et al., 2000; Fisher et al., 2014). Both dehydration and energy depletion are potential sequelae to fasting, particularly for neonatal calves on liquid diets. Creatine kinase $(\mathbf{C K})$ is an indicator of muscle fatigue or damage (Hall and Bender, 2011) and has been reported to be higher with longer transport durations under experimental conditions (Fisher et al., 2014).

Stafford et al. (2001) found that blood variable analysis results were in agreement with physical examination welfare assessments at abattoirs: calves assessed as being in an "unacceptable" state on physical examination (e.g., unable to walk, extremely weak, or seriously injured), on average, had higher PCV and urea (indicating dehydration), lower plasma glucose and higher BHB (indicating energy depletion), and higher CK (indicating muscle fatigue or damage), compared with calves that were assessed as "acceptable" on physical examination.

Previous research in an experimental setting has shown that during transport and fasting, bobby calves' plasma glucose decreases and BHB increases, indicating a negative energy balance (Todd et al., 2000; Fisher et al., 2014). Hypoglycemia can result if fasting is prolonged (24-30 h; Todd et al., 2000; Fisher et al., 2014), which is likely to compromise calf welfare. It is currently unknown how prevalent hypoglycemia is in bobby calves in a commercial setting.

Results from experimental studies have suggested that the majority of well-managed young calves that are transported up to $12 \mathrm{~h}$ and fasted up to $24 \mathrm{~h}$ have blood results, including glucose concentrations, comparable to published reference ranges for fasted young calves (Stafford et al., 2001; Fisher et al., 2014; Roadknight et al., 2021a). However, it is unclear whether controlled experimental studies are representative of bobby calf welfare in the commercial Australian dairy industry, or whether industry standards of calf management align with best-practice experimental management.

The aims of this cross-sectional observational study were (1) to assess the welfare status of bobby calves in the commercial supply chain after transport and lairage, as measured by PCV, urea, glucose, total protein, and CK; and (2) to assess whether distance and duration of transport are risk factors for poor welfare, as measured by blood parameters. We hypothesized that bobby calves in the commercial system that were transported over longer distances would be more likely to have blood variables consistent with poor welfare, such as high PCV, total protein, and urea, indicating dehydration; low glucose and high BHB, indicating depleted energy; and high CK, indicating muscle fatigue or damage.

\section{MATERIALS AND METHODS}

\section{Abattoirs}

Blood samples were collected from bobby calves at 3 commercial abattoirs in Victoria, Australia. The abattoirs were chosen because they processed large numbers of bobby calves, granted permission for research to be conducted on the premises, and were located within a reasonable proximity to the primary research institution but far enough apart to be likely to service different dairying regions.

\section{Animals}

The sample size was based on resource availability. Any calf being processed on the small stock line at the abattoir on the day of sampling was eligible for recruitment into the study; however, not every calf processed on sampling days was sampled. Calves were selected for sampling based on the next available calf where blood 
flow at exsanguination (after stunning) was sufficient for sample collection. Because samples were collected from calves as they moved along the processing line, this meant that approximately every fifth calf on the line was sampled, due to the time taken to collect, cap, rotate, and store the previous sample. Calf sex was assessed visually based on external genitalia, and calf breed was assessed based on phenotype as either Holstein-Friesian, Jersey, or crossbreed or other breed.

\section{Animal Handling}

Calves were processed as per normal abattoir practices, by abattoir staff. Calves were stunned using electrical head-only stunning, followed by exsanguination via thoracic sticking and cervical cutting. During exsanguination, National Livestock Identification System radio frequency identification (RFID) ear tags were scanned, and external numbers were read aloud into a voice recorder. This allowed each calf and the farm that it originated from to be uniquely identified.

\section{Sample Collection, Handling and Processing}

Blood samples were collected on $45 \mathrm{~d}$ between August 2017 and April 2018, corresponding to the spring 2017 and the autumn 2018 calving seasons. Samples were collected by researchers during exsanguination, as described by Roadknight et al. (2020). In brief, blood samples were collected soon after stunning, thoracic stick, and cervical cutting. Tubes (a Vacuette 8-mL serum separator clot activator tube and a Vacuette 2-mL sodium fluoride/potassium oxalate tube, both from Greiner Bio-One) were uncapped and blood was collected mid-stream directly from the thoracic stick site or from the major cervical vessels. Samples were placed immediately into a container cooled by ice packs, where they remained for transport to the laboratory.

Serum was separated by centrifuging samples at $2,500 \times g$ for $5 \mathrm{~min}$ at $4^{\circ} \mathrm{C}$. Serum was then transferred to plain tubes and frozen on the same day as sampling at $-20^{\circ} \mathrm{C}$ until analysis. Calf PCV was assessed using the microhematocrit method on the day of sampling, with blood from the sodium fluoride/potassium oxalate tube. Microhematocrit tubes were centrifuged at $9,838 \times g$ for 5 min at room temperature. After PCV measurement, plasma was separated and handled in the same manner as serum. Serum was thawed and analyzed for CK (Creatine Kinase Gen.2 Liquid Reagent, Roche), urea (Urea Kinetic Test with Urease and Glutamate Dehydrogenase, Roche), total protein (Total Protein Gen.2 colorimetric biuret, Roche), and BHB (D-3-Hydroxybutyrate kinetic enzymatic assay, Randox
Laboratories), and plasma was thawed and analyzed for glucose (Glucose HK Gen.3 enzymatic reference method with hexokinase, Roche). Biochemistry analysis was carried out using a Cobas Integra 400 Plus biochemistry analyzer (Roche) within $3 \mathrm{wk}$ of being frozen, at the U-Vet Veterinary Clinical Pathology Laboratory, University of Melbourne.

Calves were sampled on the abattoir processing line; therefore exact ages were not known. However, based on anecdotal reporting and visual inspection, the majority of calves were likely to be less than $14 \mathrm{~d}$ of age and, legally, should be at least $5 \mathrm{~d}$ old. Some biochemical and hematological values change with age in calves (Knowles et al., 2000). However, based on previous research, age-related changes in the variables measured in our study are unlikely to result in the measurements falling outside the reference interval for young calves, even if the calves were up to $30 \mathrm{~d}$ old (Knowles et al., 2000; Roadknight et al., 2021a).

\section{Distance and Duration of Transport and Lairage Calculation}

The distance that calves were transported was estimated using parish (local area) of origin information from National Livestock Identification System calf ear tags, along with Google Maps, to approximate the distance from the parish to the abattoir. The duration of transport and lairage was estimated using the RFID ear tag scanning records for 3,744 calves. Calves were scanned with an RFID tag reader by calf transporters when loaded on to the truck at the farm, and at slaughter by abattoir staff (tag reader brands unknown). These RFID scans were time-stamped and compared to calculate the total time spent in transport and lairage. Durations of more than $72 \mathrm{~h}$ (75 calves) were not included in the analysis, as we considered that these very long durations were likely due to RFID scanning or data entry error.

\section{Stopovers at Saleyards}

Some calves ( $\mathrm{n}=1,741$ ) went to a saleyard before being transported to the abattoir. Because the locations of these saleyards were not known, this was not factored into the transport distance estimate. However, time spent in saleyards was included in the duration of transport and lairage calculation. When stopovers at saleyards were included in models as factors, calves with RFID scans recorded at saleyards were recorded as "yes" for this variable, and calves with no RFID scanning records at saleyards were recorded as "no." 


\section{Statistical Analysis}

Data were analyzed using $R$ statistical software, version 4.0.0 (R Core Team, 2020). Linear mixed models were run using the lme4 and lmerTest packages (Bates et al., 2015; Kuznetsova et al., 2017), with blood variables as the dependent variables, distance transported, calf breed, calf sex, and stopovers at saleyards as fixed effects, and farm identification number as a random effect. Individual fixed effects models were fitted for all explanatory variables and were considered for the final model if $P<0.1$. Fixed effects and interaction terms were removed from the final model if they were not significant $(P>0.05)$. Model residuals were inspected for approximately normal distribution and equal variance in q-q plots, histograms, and residuals versus predicted values scatterplots. Urea and CK were natural logtransformed when used in the models, to better satisfy the model assumptions. Results for model estimates and confidence intervals for log-transformed variables were back-transformed and expressed as percentage change in the blood variable of interest.

For BHB, results for 999 calves were left censored, due to being less than the limit of detection for the analyzer $(0.1 \mathrm{mmol} / \mathrm{L})$. For this variable, maximum likelihood estimation and bootstrapping were used to calculate the mean and standard deviation, using the $\mathrm{R}$ packages MASS, boot, and fitdistrplus (Davison and Hinkley, 1997; Venables and Ripley, 2002; DelignetteMuller and Dutang, 2015; Canty and Ripley, 2019). The log normal distribution was chosen as the best fit for the data, based on visual inspection of plotted predicted versus actual values. Values for the mean and standard deviation generated in the log normal scale were then transformed to the linear scale. Linear mixed models were not used to analyze BHB, due to left censoring. Instead, a Goodman-Kruskal gamma test was run, using BHB categories of $0.59 \mathrm{mmol} / \mathrm{L}$ or less (normal) and more than $0.59 \mathrm{mmol} / \mathrm{L}$ (high), from the fasted calf reference range for BHB (Roadknight et al., 2021a). Categories of distance transported used for the Goodman-Kruskal gamma test were 0 to $199 \mathrm{~km}, 200$ to $399 \mathrm{~km}, 400$ to $599 \mathrm{~km}, 600$ to $799 \mathrm{~km}$, and more than $799 \mathrm{~km}$.

\section{RESULTS}

Samples from 4,540 calves from 1,117 farms were collected, with 4,484 of these samples being used for analysis of at least 1 blood variable. Samples from 56 calves were discarded before analysis, and not all blood variables were measured for all calves. This was due to technical reasons such as clotting of the sodium fluoride/potassium oxalate tube preventing measurement of PCV, failure to collect blood in all tubes for all calves, insufficient volume of sample, and contamination of some tubes (e.g., with hair or other foreign material). All variables were measured when there was sufficient volume and quality of blood, serum, and plasma.

Calves in this study were male (3,776 calves, $84 \%)$ and female $(481,11 \%)$, with 227 calves $(5 \%)$ for which sex was not recorded. Calves originated from Victoria (3,722 calves, $83 \%)$, New South Wales (613 calves, $14 \%$ ), and South Australia (13 calves, 0.3\%), with 136 calves $(3 \%)$ not having the state of origin identified. Calf breeds were assessed as Holstein-Friesian ( $\mathrm{n}=$ $2,079,46 \%)$, Jersey $(\mathrm{n}=903,20 \%)$, or other breed or crossbreed ( $\mathrm{n}=1,369,31 \%)$, with breed not being identified in 133 calves (3\%).

The means and medians for all blood variables measured were within the published reference intervals for fasted dairy calves aged 5 to 12 d (Roadknight et al., 2021a); see Table 1 for descriptive statistics. In addition, most individual calves' blood results were within the reference intervals (Table 2). However, a proportion of calves had values that fell outside of the reference interval. These included $36 \%$ of calves that had CK activity greater than the upper reference limit, with $1 \%$ of calves returning a CK result of more than 2,000 U/L, and $35 \%$ of calves that had total protein concentrations

Table 1. Descriptive statistics for blood variables, distance transported, and duration of transport and lairage for nonreplacement dairy calves estimated to be between 5 and $14 \mathrm{~d}$ old at 3 abattoirs, from blood collected at slaughter ${ }^{1}$

\begin{tabular}{lccccc}
\hline Variable & Mean & Median & Min & Max & SD \\
\hline PCV (L/L) & 0.30 & 0.29 & 0.11 & 0.52 & 0.06 \\
Urea (mmol/L) & 5.0 & 4.2 & 0.6 & 47.8 & 3.4 \\
Glucose (mmol/L) & 5.0 & 5.0 & 0.8 & 13.3 & 1.0 \\
BHB (mmol/L) & 0.20 & 0.16 & $<0.1$ & 2.18 & 0.15 \\
Total protein (g/L) & 59 & 58 & 9 & 4,348 & 4,345 \\
Creatine kinase (U/L) & 355 & 257 & 7 & 109 & 4,348 \\
Distance transported (km) & 245 & 180 & 8 & 1,006 & 424 \\
Duration of transport + lairage (h) & 20.0 & 19.1 & 2.3 & 47.8 & 6.3 \\
\hline
\end{tabular}

${ }^{1} \mathrm{PCV}=$ packed cell volume; $\mathrm{Min}=$ minimum; $\mathrm{Max}=$ maximum.

${ }^{2}$ Mean and SD for BHB calculated using maximum likelihood estimation and bootstrapping with a log normal distribution, then back-transformed. 
Table 2. Percentage of nonreplacement dairy calves estimated to be between 5 and $14 \mathrm{~d}$ old at 3 abattoirs that had packed cell volume (PCV) and biochemistry results, from blood samples collected at slaughter, that were outside the normal fasted calf reference interval

\begin{tabular}{lccr}
\hline Variable & $\begin{array}{c}\text { Reference } \\
\text { interval }^{1}\end{array}$ & $\begin{array}{c}\text { No. of calves with results } \\
\text { < lower reference limit }(\%)\end{array}$ & $\begin{array}{c}\text { No. of calves with results } \\
\text { > upper reference limit }(\%)\end{array}$ \\
\hline PCV (L/L) & $0.23-0.45$ & $208(12.1 \%)$ & $7(0.4 \%)$ \\
Urea (mmol/L) & $1.6-7.7$ & $78(1.8 \%)$ & $472(11 \%)$ \\
Glucose (mmol/L) & $2.8-6.9$ & $60(1.4 \%)$ & $100(2.3 \%)$ \\
BHB (mmol/L) & $<0.60$ & $\mathrm{~N} / \mathrm{A}^{2}$ & $91(2.1 \%)$ \\
Total protein (g/L) & $45-82$ & $656(15.1 \%)$ & $192(4.4 \%)$ \\
Creatine kinase (U/L) & $46-326$ & $4(0.1 \%)$ & $1,548(35.6 \%)$ \\
\hline
\end{tabular}

${ }^{1}$ From Roadknight et al. (2021a).

${ }^{2} \mathrm{~N} / \mathrm{A}=$ not applicable.

consistent with failure of passive transfer (total protein of $52 \mathrm{~g} / \mathrm{L}$ or less; Cuttance et al., 2017).

The distance that calves were transported had significant effects on all blood variables except for urea (Table 3) and BHB. We detected no significant association between the distance transported category and the BHB category $(\gamma=0.05 ; 95 \%$ CI: $-0.17,0.27)$. Visual examination of a loess line (a nonparametric, locally estimated scatterplot smoothing regression line) fitted to a plot of glucose and distance transported, suggested that, for calves being transported more than approximately $500 \mathrm{~km}$, each kilometer traveled was associated with a greater decline in glucose compared with calves transported shorter distances (Figure 1). This was confirmed when a linear mixed model was used to analyze only those calves being transported more than $500 \mathrm{~km}$ : glucose declined by an estimated $0.41 \mathrm{mmol} / 100 \mathrm{~km}$ for these calves $(95 \% \mathrm{CI}:-0.5,-0.3 ; P<0.001)$, an 8-fold increase on calves traveling all distances $(-0.05$ mmol/100 km; Table 3).

No significant effects of duration of transport and lairage were evident for any of the blood variables (Roadknight et al., 2021b). Few calves $(6.5 \%)$ had recorded duration of transport and lairage times of more than $24 \mathrm{~h}$; the highest recorded duration of transport and lairage was $48 \mathrm{~h}$. No significant effects of stopovers at saleyards on any of the blood variables $(P>0.1)$ were detectable, except for total protein: calves that had a stopover were estimated to have total protein that was $2.5 \mathrm{~g} / \mathrm{L}$ lower than calves that did not have a stopover (95\% CI: $-3.5,-1.5 ; P<0.001$; Table 3). Farm of origin accounted for $20 \%$ of the random variability in glucose, $11 \%$ of the random variability in total protein, $6 \%$ of the random variability in PCV, $11 \%$ of the random variability in urea, and $17 \%$ of the random variability in CK.

Table 3. Final linear mixed model results for glucose, packed cell volume (PCV), urea (log-transformed), and creatine kinase (CK, logtransformed $)^{1}$

\begin{tabular}{|c|c|c|c|c|c|c|}
\hline Outcome variable & Explanatory variable & Estimate of effect & $95 \% \mathrm{CI}$ & $P$-value & $\begin{array}{l}\text { No. of } \\
\text { calves }\end{array}$ & $\begin{array}{l}\text { No. of } \\
\text { farms }\end{array}$ \\
\hline \multirow[t]{3}{*}{ Glucose (mmol/L) } & Transport distance & $-0.05 / 100 \mathrm{~km}$ & $(-0.07,-0.03)$ & $<0.001$ & 3,950 & 1,039 \\
\hline & Breed (Holstein-Friesian) & Reference & - & - & 3,950 & 1,039 \\
\hline & Breed (other/crossbreed) & -0.03 & $(-0.10,0.04)$ & 0.372 & 3,950 & 1,039 \\
\hline \multirow[t]{2}{*}{$\mathrm{PCV}(\mathrm{L} / \mathrm{L})$} & Transport distance & $0.002 / 100 \mathrm{~km}$ & $(0.0003,0.004)$ & 0.020 & 1,573 & 612 \\
\hline & Breed (Holstein-Friesian) & Reference & - & - & 1,573 & 612 \\
\hline \multirow[t]{3}{*}{ Urea (\% change) } & Breed (Holstein-Friesian) & Reference & - & - & 4,227 & 1,088 \\
\hline & Breed (Jersey) & 6.3 & $(1.8,11.1)$ & 0.005 & 4,227 & 1,088 \\
\hline & Breed (other/crossbreed) & 0.6 & $(-3.0,4.2)$ & 0.758 & 4,227 & 1,088 \\
\hline \multirow{4}{*}{ Total protein $(\mathrm{g} / \mathrm{L})$} & Transport distance & $0.5 / 100 \mathrm{~km}$ & $(0.3,0.7)$ & $<0.001$ & 3,954 & 1,034 \\
\hline & Breed (Holstein-Friesian) & Reference & - & - & 3,954 & 1,034 \\
\hline & Breed (Jersey) & 5.5 & $(4.3,6.6)$ & $<0.001$ & 3,954 & 1,034 \\
\hline & Breed (other/crossbreed) & 5.3 & $(4.4,6.3)$ & $<0.001$ & 3,954 & 1,034 \\
\hline
\end{tabular}

${ }^{1}$ Farm of origin was included as a random effect. For transformed variables, estimates and confidence intervals have been back-transformed, so are expressed as percentage change in the outcome variable. Because there was a significant interaction between distance and sex for CK, we present estimates for the effect of distance for both males and females in the final model. 


\section{DISCUSSION}

Our results show that, although most bobby calves sampled had blood results within the established young calf reference intervals for fasted, nontransported calves (Roadknight et al., 2021a), some had results outside of this range. Blood measurements outside of reference intervals could be due to calf management factors on farm or the effects of transport, and they indicate the potential for physiological and welfare compromise for some calves in the supply chain. For example, we found evidence of dehydration in approximately $11 \%$ of calves, with urea concentrations higher than the upper reference limit. Although urea can increase with starvation, it has been reported that this does not occur in neonatal calves until the third day of fasting (Dalton, 1967); therefore factors other than fasting time may be contributing to the increase in urea concentration. Such factors could include diarrhea or other illness, restricted milk feeding, and lack of water availability on the farm. Previous research has reported that Australian dairy farmers start providing access to water on average at $5 \mathrm{~d}$ of calf age (Phipps, 2016), despite industry recommendations to provide water from the day of birth (Dairy Australia, 2017). Therefore, it is possible that some bobby calves did not have access to water before being transported, and this may have contributed to dehydration, causing high urea concentrations.
However, PCV, which is another measure of hydration, showed evidence of dehydration in only $0.4 \%$ of calves. But $12 \%$ of calves had PCV results consistent with mild to moderate anemia, so the effects of dehydration could be masked due to this tendency toward anemia. The cause and the importance of the anemia in the present study is unknown; previous research in young calves has suggested correlations between anemia and diarrhea (Prodanović et al., 2019), and iron deficiency has been theorized to be involved in the etiology of anemia in other studies (Hibbs et al., 1963; Benesi et al., 2019). Therefore, the tendency toward anemia is suggestive of underlying pathology or deficiency, either of which could affect calf welfare. However, further research would be needed to confirm this.

Most bobby calves had energy profiles consistent with reference intervals from nontransported calves fasted for 14 to $25 \mathrm{~h}$ (Roadknight et al., 2021a). Very few calves at abattoirs showed evidence of hypoglycemia or had high BHB. However, it should be noted that calves fasted for 14 to $25 \mathrm{~h}$ may not reflect an ideal welfare state, although this does reflect standard calf management practice on Australian dairy farms, where feeding generally occurs once or twice daily. Therefore, the low proportions of calves at abattoirs with hypoglycemia and high BHB does not mean that calves were not hungry or low in energy reserves. Rather, it suggests that they had similar glucose and BHB concentrations

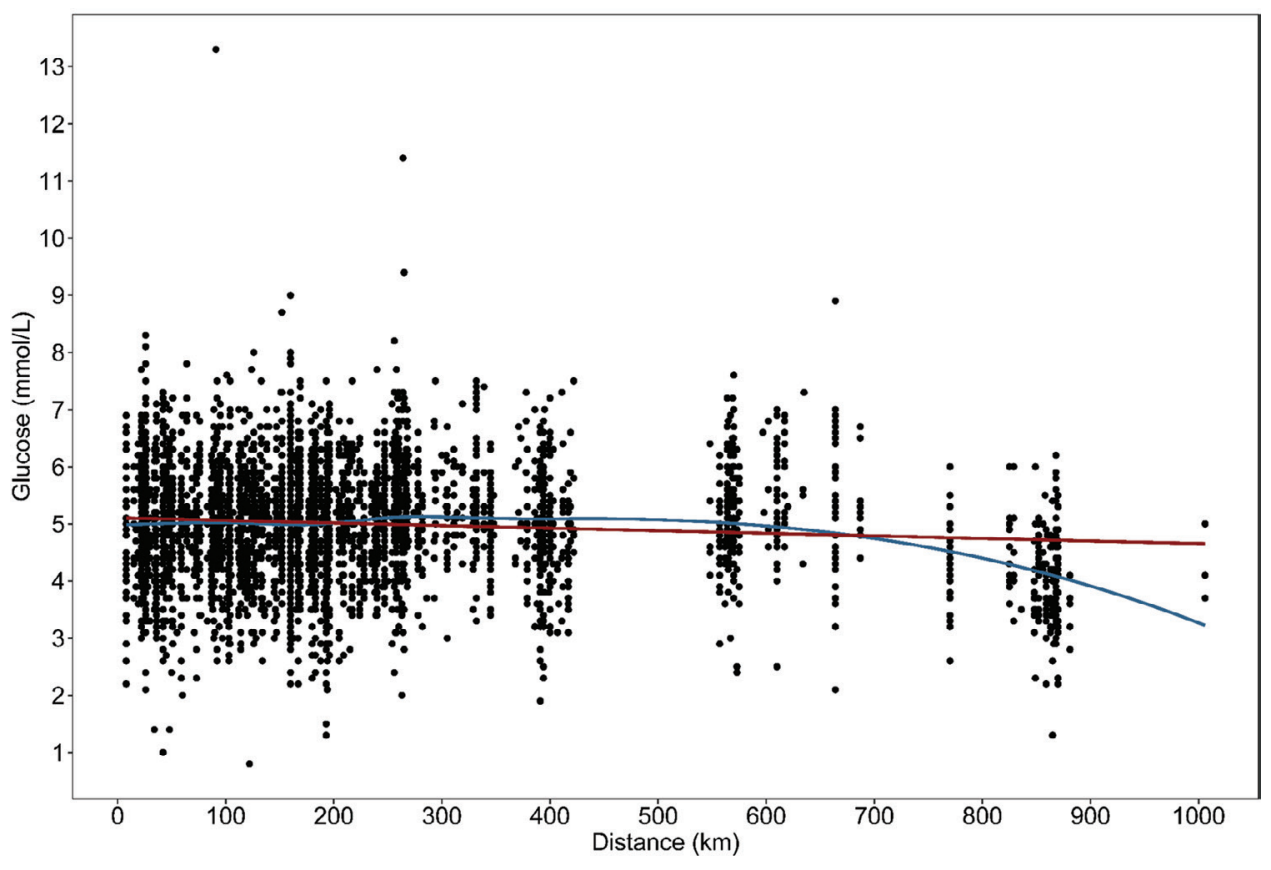

Figure 1. The relationship of plasma glucose to estimated distance transported from farm to abattoir, for 3,950 nonreplacement dairy calves, estimated to be between 5 and $14 \mathrm{~d}$ old. Red line is the linear regression line; blue line is a loess line, which is a nonparametric, locally estimated scatterplot smoothing regression line. 
to fasted, nontransported calves. Most bobby calves sampled at abattoirs appeared to have been fasted for $24 \mathrm{~h}$ or less, based on comparisons of glucose concentrations with calves fasted for a known time period (Fisher et al., 2014; Roadknight et al., 2021a).

Creatine kinase is a sensitive indicator of muscle fatigue or damage (Hall and Bender, 2011). Muscle fatigue or damage during transport could occur due to calves bracing against truck movements, or from bruising due to knocks or falls. In the current study, $36 \%$ of calves had CK results greater than the young calf CK upper reference limit for nontransported calves, reported in Roadknight et al. (2021a). This was not unexpected, as CK is known to increase with transport, even under experimental conditions (Todd et al., 2000; Fisher et al., 2014). The mean and median CK values were comparable to transported calf CK activity reported in previous research, in both experimental and commercial settings (Todd et al., 2000; Stafford et al., 2001; Fisher et al., 2014), indicating that most calves had CK activity consistent with expected CK values after transport. However, $1 \%$ of calves had what could be considered moderately high to high CK activity (more than 2,000 U/L; Hall and Bender, 2011), indicating the possibility for welfare compromise due to bruising or fatigue in these animals.

Creatine kinase has a short half-life of approximately $4 \mathrm{~h}$ in cattle (Parkinson et al., 2019), so the timing of sample collection in relation to muscle damage will affect CK activity results. In the present study, samples were taken after overnight lairage, so CK activity may have decreased with this rest period. However, the sampling techniques used may have increased CK activity, as blood collection at exsanguination in calves leads to, on average, $102 \%$ higher CK activity (Roadknight et al., 2020).

The effect of distance traveled on most blood variables was in the direction expected. For example, PCV and total protein increased with longer distances of transport, indicating a trend toward dehydration with longer distances. Similarly, glucose decreased with longer transport distances, indicating longer fasting times or greater energy utilization with long transport distances. However, CK decreased with increasing distance transported, which was unexpected, as CK usually increases with transport (Grigor et al., 2001; Marcato et al., 2020), and more so with longer transport durations (Fisher et al., 2014). We theorize that this may be due to loading being the most likely process to increase CK levels, due to knocks, falls, or resistance to handling. If this was the case, calves transported for longer distances may also have a longer time to recover to normal CK activity after muscle insult.
Urea and BHB were not significantly affected by distance transported. For urea, previous nutrition and access to water may be more important than the distance that calves traveled. For BHB, some calves with low body fat reserves may not show a marked increase in this variable with a negative energy balance. Additionally, using the Goodman-Kruskal gamma test for statistical analysis for BHB may have masked small distance effects, as some detail was lost by dividing the data into categories, in contrast to the linear mixed models used for other variables, which allowed a more detailed understanding of the effect of distance on the variables.

Although distance transported had significant effects on all blood variables except urea and BHB, most of the effects estimated by the models were very small. For example, glucose was estimated to decrease by 0.05 $\mathrm{mmol} / \mathrm{L}$ per $100 \mathrm{~km}$, and PCV to increase by 0.002 $\mathrm{L} / \mathrm{L}$. When a subset of calves that were transported more than $500 \mathrm{~km}$ were analyzed, we found that glucose declined more with each kilometer of transport for these calves, compared with calves overall (Figure 1). For calves transported for more than $500 \mathrm{~km}$, glucose decreased 8 times faster per kilometer transported compared with calves overall. This suggests that the welfare impact of transport may be greater per kilometer if calves have already been transported over a long distance.

We found no significant effects of stopovers at saleyards on any of the blood variables, except for a minor effect on total protein. Possible reasons for this general lack of effect may be that some calves may have stopped at saleyards but not been RFID scanned, or calves may have been fed during the stopover, which could negate some of the negative effects of fasting and transport time. However, it is also possible that stopovers had little or no influence on the variables measured.

Farm of origin, when included in the final model for glucose, accounted for $20 \%$ of the random variation in glucose and $11 \%$ of the random variation in total protein between calves. Estimates of the effect of farm suggested that the farm of origin had a relatively large effect on plasma glucose and serum total protein. For instance, when analyzing a subset of calves from farms where more than 5 calves were included in the data set, the estimated difference in plasma glucose between the $2.5 \%$ and the $97.5 \%$ quantile was $1.1 \mathrm{mmol} / \mathrm{L}$, but the estimated effect of distance transported for the same group of calves was only $-0.05 \mathrm{mmol} / \mathrm{L}$ per $100 \mathrm{~km}$. Plasma glucose could reflect the nutritional or health status of calves from particular farms, with unwell calves being likely to have lower plasma glucose due to inappetence. For total protein, there was a difference 
of $12.4 \mathrm{~g} / \mathrm{L}$ between these quantiles for farms, but the effect of distance transported for the same cohort was estimated to be only $0.5 \mathrm{~g} / \mathrm{L}$ per $100 \mathrm{~km}$. Although it is difficult to compare the magnitude of fixed and random effects directly, these results suggest that factors related to calves' farm of origin may have relatively large implications for calf welfare, compared with transport distance.

The reasons why the duration of transport and lairage had no significant effects on most blood variables could be because of inaccuracies in RFID scanning data, effects of stopovers, such as at saleyards, where some calves may have been fed, and the fact that lairage and transport duration could only be assessed together. For example, it is possible that transport but not lairage had an influence on calf blood variables, or that they had opposing effects, making interpretation of this variable difficult.

Although $6.5 \%$ of calves had transport and lairage durations of more than $24 \mathrm{~h}$ recorded, this may not reflect the calves' time off feed, as calves may be fed at saleyards. Anecdotally, it has been reported that calves from New South Wales may be fed at the saleyards before traveling to Victoria.

One limitation of this study is the sampling technique. Blood collection at exsanguination is likely to have affected CK measurements and may also have had some minor effects on plasma glucose and total protein measurements (Roadknight et al., 2020). The sampling technique is unlikely to have affected PCV, urea, and BHB results (Roadknight et al., 2020).

Another limitation of this study is that calves that were suffering very poor welfare may not have been sampled. Because sampling occurred at slaughter, only calves that were considered fit enough for transport, lairage, and slaughter, as assessed by farmers, transporters, and abattoir staff, would survive until the end of the commercial supply chain; others may have died or been euthanized before this point. We suggest that future research on bobby calf welfare be directed toward quantifying calf morbidity and mortality rates between birth and slaughter.

\section{CONCLUSIONS}

For the variables measured, most calves' blood measurements at abattoirs fell within the fasted, nontransported calf reference range (Roadknight et al., 2021a). Low proportions of calves showed evidence of hypoglycemia, high BHB, or CK activity suggestive of welfare compromise. However, $11 \%$ of calves had elevated urea, suggesting dehydration, and $12 \%$ were anemic due to unknown etiology. Longer distances affected calves' plasma glucose more per kilometer transported than transport distance overall. However, the estimated effects of transport distance on calves' blood variables were small, even for calves traveling more than $500 \mathrm{~km}$. As expected, longer transport distances were associated with higher PCV and total protein concentration, and lower plasma glucose. Unexpectedly, CK had an inverse relationship with distance transported; this may be related to the short half-life of CK in cattle, and where in the supply chain the highest risk of muscle insult occurred. A reasonable proportion of the variability between calves in blood measurements could be accounted for by farm of origin. Further research on bobby calf welfare should aim to quantify morbidity and mortality data in the commercial nonreplacement calf supply chain, from birth to slaughter.

\section{ACKNOWLEDGMENTS}

The authors gratefully thank the staff at all participating abattoirs for allowing the use of their animals and access to facilities. We appreciate the generous assistance of our associates at the Department of Jobs, Precincts and Regions, who provided us with data on the duration of calf lairage and transport. We also warmly acknowledge our colleagues who helped with sample collection and processing: Laura Field, Pablo Alvarez, and Andrew Carlyon, from the Animal Welfare Science Centre at the University of Melbourne; and Fiona Armour, Daniel Pilbeam, Debra Kirkham, and Amanda Hall from U-Vet Clinical Pathology Laboratory at the University of Melbourne. Thanks also to Andrew Woodward (Melbourne Veterinary School, University of Melbourne) for advice on statistical calculations and methods, and for providing the $\mathrm{R}$ source code for the bootstrapping methods used in this paper. We also acknowledge the contribution of 2 anonymous reviewers, whose comments on earlier drafts of this manuscript helped to improve the quality of the final draft. This work was supported by Meat and Livestock Australia, Lactalis Australia, an Australian Government Research Training Program Scholarship, and a Meat and Livestock Australia Postgraduate Scholarship/Study Award. The authors have not stated any conflicts of interest.

\section{REFERENCES}

Abuelo, A., P. Havrlant, N. Wood, and M. Hernandez-Jover. 2019. An investigation of dairy calf management practices, colostrum quality, failure of transfer of passive immunity, and occurrence of enteropathogens among Australian dairy farms. J. Dairy Sci. 102:8352-8366. https://doi.org/10.3168/jds.2019-16578.

Animal Health Australia. 2012. Australian Animal Welfare Standards and Guidelines-Land Transport of Livestock. Accessed Feb. 28, 2018. http://www.animalwelfarestandards.net.au/land-transport/. 
Bates, D., M. Mächler, B. Bolker, and S. Walker. 2015. Fitting linear mixed-effects models using lme4. J. Stat. Softw. 67:1-48. https:// doi.org/10.18637/jss.v067.i01.

Bell, A. W. 1979. Lipid metabolism in liver and selected tissues and in the whole body of ruminant animals. Prog. Lipid Res. 18:117-164. https://doi.org/10.1016/0163-7827(79)90013-4.

Benesi, F. H., J. A. N. Lisbôa, M. L. R. Leal, C. L. Shecaira, and R. B. dos Santos. 2019. Occurrence of anemia in Holstein calves in the first month after birth. Ciências Agrárias 40:1139-1144. https: //doi.org/10.5433/1679-0359.2019v40n3p1139.

Canty, A. and B. Ripley. 2019. boot: Bootstrap R (S-plus) functions. $\mathrm{R}$ package version 1.3-24. Accessed Apr. 28, 2021. https://cran.r -project.org/web/packages/boot/citation.html.

Cockram, M. S., and J. Y. Spence. 2012. The effects of driving events on the stability and resting behaviour of cattle, young calves and pigs. Anim. Welf. 21:403-417. https://doi.org/10.7120/09627286 .21.3.403

Cuttance, E. L., W. A. Mason, R. A. Laven, J. McDermott, and C. V. C. Phyn. 2017. Prevalence and calf-level risk factors for failure of passive transfer in dairy calves in New Zealand. N. Z. Vet. J. 65:297-304. https://doi.org/10.1080/00480169.2017.1361876.

Dairy Australia. 2017. Rearing Healthy Calves. 2nd ed. Accessed Jan. 15, 2019. https://www.dairyaustralia.com.au/-/media/ dairyaustralia/documents/farm/animal-care/animal-welfare/calf -welfare/rearing-healthy-calves-manual-2nd-ed.pdf.

Dalton, R. G. 1967. The effect of starvation on the fluid and electrolyte metabolism of neonatal calves. Br. Vet. J. 123:237-246. https: //doi.org/10.1016/S0007-1935(17)39954-2.

Davison, A. C., and D. V. Hinkley. 1997. Bootstrap Methods and Their Applications. Cambridge University Press.

Delignette-Muller, M. L., and C. Dutang. 2015. fitdistrplus: An R package for fitting distributions. J. Stat. Softw. 64:1-34. https:// doi.org/10.18637/jss.v064.i04.

Fisher, A. D., B. H. Stevens, M. J. Conley, E. C. Jongman, M. C. Lauber, S. J. Hides, G. A. Anderson, D. M. Duganzich, and P. D. Mansell. 2014. The effects of direct and indirect road transport consignment in combination with feed withdrawal in young dairy calves. J. Dairy Res. 81:297-303. https://doi.org/10.1017/ S0022029914000193.

Grandin, T. 1997. Assessment of stress during handling and transport. J. Anim. Sci. 75:249-257. https://doi.org/10.2527/1997.751249x.

Grigor, P. N., M. S. Cockram, W. B. Steele, C. J. Le Sueur, R. E. Forsyth, J. A. Guthrie, A. K. Johnson, V. Sandilands, H. W. Reid, C. Sinclair, and H. K. Brown. 2001. Effects of space allowance during transport and duration of mid-journey lairage period on the physiological, behavioural and immunological responses of young calves during and after transport. Anim. Sci. 73:341-360. https:// doi.org/10.1017/S135772980005832X.

Hall, R. L., and H. S. Bender. 2011. Muscle. Pages 283-294 in Duncan and Prasse's Veterinary Laboratory Medicine: Clinical Pathology. 5th ed. K. S. Latimer, ed. Wiley-Blackwell.

Hibbs, J. W., H. R. Conrad, J. H. Vandersall, and C. Gale. 1963. Occurrence of iron deficiency anemia in dairy calves at birth and its alleviation by iron dextran injection. J. Dairy Sci. 46:1118-1124. https://doi.org/10.3168/jds.S0022-0302(63)89219-X.

Hulbert, L. E., and S. J. Moisá. 2016. Stress, immunity, and the management of calves. J. Dairy Sci. 99:3199-3216. https://doi.org/10 $.3168 /$ jds.2015-10198

Jongman, E. C., and K. L. Butler. 2013. Ease of moving young calves at different ages. Aust. Vet. J. 91:94-98. https://doi.org/10.1111/ avj.12014.

Knowles, T. G. 1999. A review of the road transport of cattle. Vet. Rec. 144:197-201. https://doi.org/10.1136/vr.144.8.197.

Knowles, T. G., J. E. Edwards, K. J. Bazeley, S. N. Brown, A. Butterworth, and P. D. Warriss. 2000. Changes in the blood biochemical and haematological profile of neonatal calves with age. Vet. Rec. 147:593-598. https://doi.org/10.1136/vr.147.21.593

Knowles, T. G., P. D. Warriss, S. N. Brown, J. E. Edwards, P. E. Watkins, and A. J. Phillips. 1997. Effects on calves less than one month old of feeding or not feeding them during road transport of up to 24 hours. Vet. Rec. 140:116-124. https://doi.org/10.1136/ vr.140.5.116.
Kuznetsova, A., P. B. Brockhoff, and R. H. B. Christensen. 2017. lmerTest Package: Tests in linear mixed effects models. J. Stat. Softw. 82:1-26. https://doi.org/10.18637/jss.v082.i13.

Marcato, F., H. van den Brand, B. Kemp, B. Engel, M. WolthuisFillerup, and K. van Reenen. 2020. Effects of pretransport diet, transport duration, and type of vehicle on physiological status of young veal calves. J. Dairy Sci. 103:3505-3520. https://doi.org/10 $.3168 /$ jds.2019-17445.

New Zealand Government. 2018. Animal Welfare (Care and Procedures) Regulations 2018. Accessed Oct. 29, 2018. http://www .legislation.govt.nz/regulation/public/2018/0050/latest/whole .html.

Parkinson, T. J., J. J. Vermunt, J. Malmo, and R. A. Laven. 2019. Diseases of Cattle in Australasia. 2nd ed. Massey University Press.

Phipps, A. J. 2016. Colostrum management practices and effects on colostrum quality on commercial northern Victorian dairy farms. MVSc thesis. Faculty of Veterinary and Agricultural Sciences, University of Melbourne, Parkville, Victoria, Australia.

Prodanović, R., S. Nedić, O. Radanović, V. Milićević, I. Vujanac, J. Bojkovski, B. Kureljušić, S. Arsić, L. Jovanović, and D. Kirovski. 2019. Occurrence of neonatal diarrhea in calves with irondeficiency anemia. Vet. Glas. 73:1-9. https://doi.org/10.2298/ VETGL181210011P.

R Core Team. 2020. R: A language and environment for statistical computing. Vol. 4.0.0. R Foundation for Statistical Computing.

Roadknight, N., N. Courtman, P. Mansell, E. Jongman, S. ClarkeErrey, and A. Fisher. 2020. Blood collection from dairy calves at exsanguination post-slaughter yields similar biochemical and packed cell volume measurements compared with in vivo collection during lairage. Res. Vet. Sci. 130:41-47. https://doi.org/10.1016/ j.rvsc.2020.02.013.

Roadknight, N., N. Courtman, P. Mansell, E. Jongman, Z. Loh, and A. Fisher. 2021a. Biochemistry, hematology and electrolyte reference intervals for dairy calves aged 5-12 days. Vet. Clin. Pathol. 00:1-9. https://doi.org/10.1111/vcp.12955.

Roadknight, N., P. Mansell, E. Jongman, N. Courtman, D. McGill, G. Hepworth, and A. Fisher. 2021b. Supplementary materials for Roadknight et al.: Blood parameters of young calves at abattoirs are related to distance transported and farm of origin. https://doi .org/10.6084/m9.figshare.14339096.v2.

Stafford, K. J., D. J. Mellor, S. E. Todd, N. G. Gregory, R. A. Bruce, and R. N. Ward. 2001. The physical state and plasma biochemical profile of young calves on arrival at a slaughter plant. N. Z. Vet. J. 49:142-149. https://doi.org/10.1080/00480169.2001.36222.

Todd, S. E., D. J. Mellor, K. J. Stafford, N. G. Gregory, R. A. Bruce, and R. N. Ward. 2000. Effects of food withdrawal and transport on 5- to 10-day-old calves. Res. Vet. Sci. 68:125-134. https://doi .org/10.1053/rvsc.1999.0345.

Trunkfield, H. R., and D. M. Broom. 1990. The welfare of calves during handling and transport. Appl. Anim. Behav. Sci. 28:135-152. https://doi.org/10.1016/0168-1591(90)90050-N.

Venables, W. N., and B. D. Ripley. 2002. Modern Applied Statistics with S. 4th ed. Springer.

Vogels, Z., G. M. Chuck, and J. M. Morton. 2013. Failure of transfer of passive immunity and agammaglobulinaemia in calves in southwest Victorian dairy herds: Prevalence and risk factors. Aust. Vet. J. 91:150-158. https://doi.org/10.1111/avj.12025.

Warriss, P. D., S. N. Brown, T. G. Knowles, S. C. Kestin, J. E. Edwards, S. K. Dolan, and A. J. Phillips. 1995. Effects on cattle of transport by road for up to 15 hours. Vet. Rec. 136:319-323. https: //doi.org/10.1136/vr.136.13.319.

\section{ORCIDS}

Natalie Roadknight @ https://orcid.org/0000-0002-5460-7532 Peter Mansell @ https://orcid.org/0000-0001-7216-2947 Ellen Jongman ๑ https://orcid.org/0000-0002-7504-0280 Natalie Courtman (1) https://orcid.org/0000-0003-0947-3261 Graham Hepworth @ https://orcid.org/0000-0003-3061-7186 Andrew Fisher $\odot$ https://orcid.org/0000-0002-2505-2160 